\title{
Cultivar bajo las bombas: La agricultura urbana y periurbana en Barcelona durante la Guerra Civil, 1936-1939
}

\author{
Marta Camps Calvet, Santiago Gorostiza y David Saurí
}

\begin{abstract}
PALABRAS CLAVE: guerra civil española, agricultura urbana y periurbana, anarcosindicalismo, colectivizaciones.
\end{abstract}

\section{CÓDIGOS JEL: P32, N54, N94, Q15.}

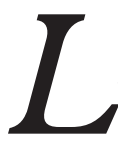

a agricultura urbana es clave en momentos en que la seguridad alimentaria se encuentra amenazada, como es el caso de los conflictos bélicos, que alteran los sistemas de producción, conservación, transporte y distribución de alimentos. Durante las dos guerras mundiales, distintos gobiernos movilizaron a la población civil para participar en la producción de alimentos y aumentar la moral a través de la contribución a la guerra desde la retaguardia. A diferencia de estos casos, la producción de alimentación en las ciudades españolas durante la guerra civil de 1936-1939 ha recibido escasa atención. Mediante documentación de distintos archivos públicos y privados, prensa histórica y testimonios personales, este artículo explora la historia socioambiental de la producción agrícola en la ciudad de Barcelona durante la guerra civil española. Por una parte, se analiza la colectivización de la agricultura en el término municipal de Barcelona, realizada por la Colectividad Agrícola de Barcelona y su Radio (CNT), que alcanzó un máximo de 3.500 personas trabajadoras y gestionó unas 850 hectáreas de cultivos. Dicha Colectividad convivió con una gran expansión de los huertos familiares de autoconsumo, a medida que el suministro de la ciudad se deterioraba. En conjunto, ambas contribuyeron a mantener un precario suministro de alimentos hasta la ocupación de la ciudad por parte de las tropas franquistas en enero de 1939. 


\title{
Growing food under fire: Urban and peri-urban agriculture in Barcelona during the Spanish Civil War, 1936-1939
}

\section{KEYWORDS: Spanish Civil War, urban and peri-urban agriculture, anarcho-syndicalism, collectivisations.}

\author{
JEL CODES: P32, N54, N94, Q15.
}

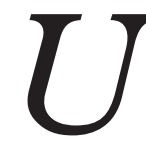

rban agriculture is key when food security is threatened, as in the cases of wars, which disrupt food production, conservation, transportation, and distribution systems. During the two World Wars of the $20^{\text {th }}$ century, governments mobilized civilians to participate in food production and to increase morale by contributing to the war effort from the rearguard. Unlike these cases, food production in Spanish cities during the civil war of 1936-1939 has received little attention. Using documentation from different public and private archives, press clips, and personal testimonies, this article explores the socio-environmental history of agricultural production in Barcelona during the Spanish Civil War. On the one hand, we analysed the collectivization of agriculture in the municipality of Barcelona, carried out by the Colectividad Agricola de Barcelona y su Radio (CNT), involving at its peak some 3,500 workers managing 850 hectares of crops. On the other hand, this Collective coexisted with an expansion of home gardens for self-consumption in the city as food supplies became scarcer. Both initiatives contributed to maintaining a precarious food supply until the occupation of the city by Franco's troops in Fanuary 1939.

Recepción: 2020-06-15 - Revisión: 2020-10-29 • Aceptación: 2020-11-15

Marta Camps Calvet [orcid.org/0000-0001-8704-2649] es doctoranda en Geografía de la Universitat Autònoma de Barcelona. Dirección para correspondencia: Departament de Geografia, Facultat de Filosofia $i$ Lletres, Universidad Autónoma de Barcelona, 08193 Bellaterra (Barcelona).C.e. martacampsc@gmail.com

Santiago Gorostiza [orcid.org/0000-0002-8516-5642] es investigador postdoctoral en el Centre d'Histoire de Sciences Po. Dirección para correspondencia: Centre d'Histoire de Sciences Po, 27 rue Saint-Guillaume, 75337 Paris. C.e.santiago.gorostiza@sciencespo.fr

David Saurí Pujol [orcid.org/0000-0002-3618-7773] es catedrático de Geografía Humana en la Universitat Autònoma de Barcelona. Dirección para correspondencia: Departamentde Geografia, Facultat de Filosofia $i$ Lletres, Universidad Autónoma de Barcelona, 08193 Bellaterra (Barcelona). C.e. david.sauri@uab.cat 


\section{INTRODUCCIÓN}

El 20 de agosto de 1938 el semanario anarcosindicalista ;Campo Libre! celebraba una decisión tomada por las organizaciones antifascistas de la ciudad de Madrid. «Los solares y terrenos de Madrid no pueden estar improductivos", titulaba el órgano de la Federación Regional de Campesinos y Alimentación del Centro. El artículo anunciaba que todas las parcelas no cultivadas serían destinadas a la producción de verduras y hortalizas, utilizando solares y jardines de dentro y fuera del casco urbano madrileño, con la finalidad de mejorar el abastecimiento de la población. «Hay que recordar la producción de verduras y hortalizas en Barcelona y su extrarradio", proseguía, ciudad donde miles de personas se habían agrupado y empezado a trabajar las tierras en común. El artículo destacaba que, con ocasión de la colectivización de la tierra en Cataluña, se había entendido «hasta qué punto era trascendente la agricultura urbana» ${ }^{1}$.

¡Campo Libre! se refería a la Colectividad Agrícola de Barcelona y su Radio, que en aquellas fechas daba empleo a cerca de 2.500 personas en el cultivo de unas 850 hectáreas del término municipal barcelonés ${ }^{2}$. Pero la explotación colectiva fue solo una de las formas que adoptó la expansión del cultivo de la tierra en la ciudad durante la guerra civil española. Lejos de los frentes durante la mayor parte del conflicto, y con problemas de abastecimiento desde finales de 1936, Barcelona vio aparecer multitud de pequeños huertos en parterres, solares y fincas abandonadas. La ocupación de estos espacios por parte de la población civil transformó el paisaje urbano ostensiblemente. Varios grupos escolares establecieron sus propios huertos, a la vez que se organizaban granjas-escuela para cuidar de los niños y niñas refugiados. Algunas empresas colectivizadas repartieron pequeñas fincas entre sus trabajadores y trabajadoras, mientras que en otras los obreros y obreras organizaron su propio huerto. Avanzada la guerra, se calculaba que había al menos diez mil huertos familiares en la ciudad, cuyas conexiones irregulares a la red de suministro de agua causaron protestas por parte de la empresa colectivizada Aguas de Barcelona ${ }^{3}$. Aproximadamente en las mismas fechas de agosto de 1938 en que Madrid aprobaba roturar los solares y tierras no cultivadas, el presidente de la Generalitat de Catalunya firmaba un decreto destinado a regular la transformación de terrenos viales, solares y yermos de núcleos urbanos en huertos familiares (Generalitat de Catalunya, 1938a).

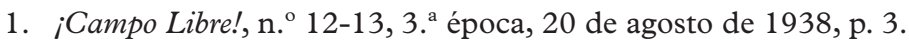

2. Arxiu Nacional de Catalunya (ANC), ANC1-886-T-13819, "Memoria de la Colectividad Agrícola de Barcelona y su Radio", septiembre de 1938.

3. Arxiu Municipal Contemporani de Barcelona (AMCB), exp. n. ${ }^{\circ}$ GM-895, cód. A183 Comissió de Governació, "Petició de l'Agrupació de Montjuïch referent al Decret de la Generalitat de 10 d'agost de $1938 \mathrm{i}$ el tribut sobre la terra dels horts familiars». Sobre Aguas de Barcelona, véase LaVanguardia, 19 de agosto de 1937, p. 2. 


\section{FIGURA 1}

Término municipal de Barcelona, 1929

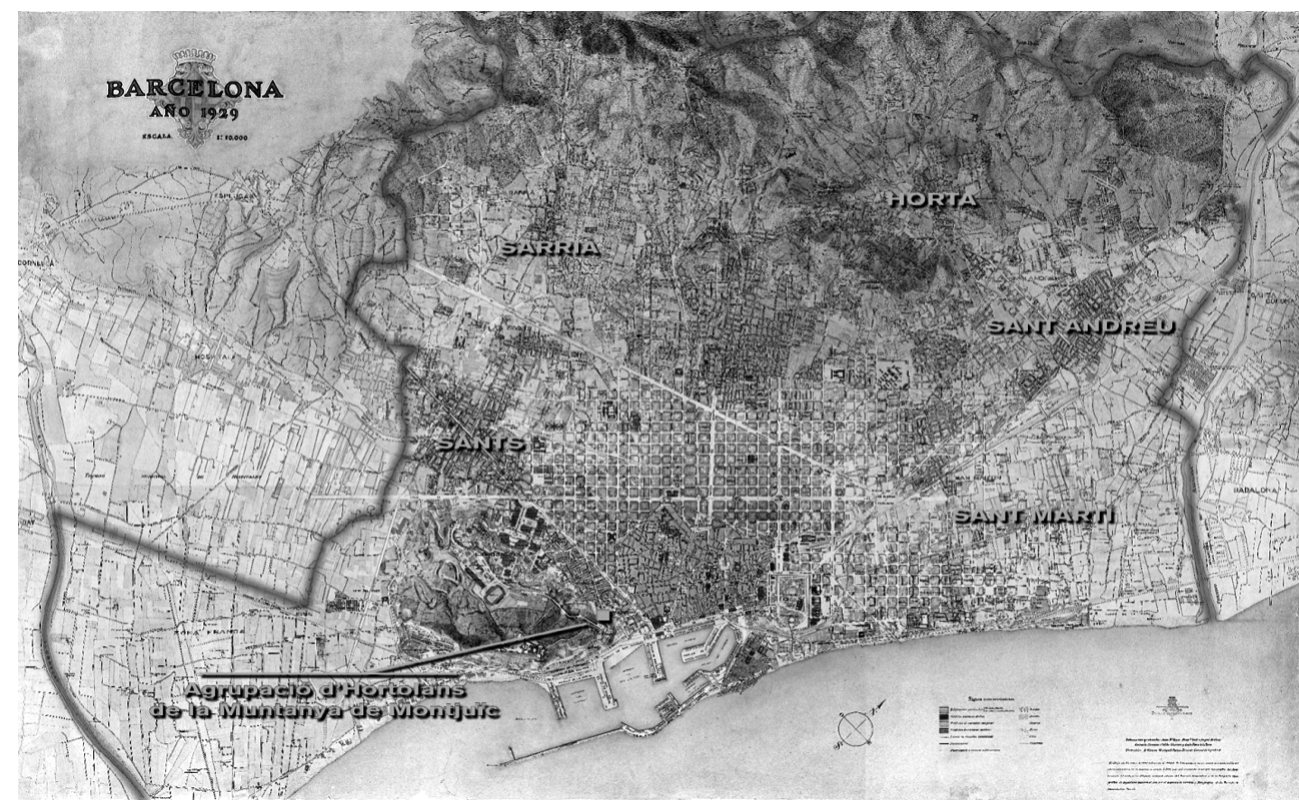

Fuente: elaboración propia a partir del mapa de Barcelona (AMCB).

El presente artículo expone la variedad e importancia de las prácticas agrícolas urbanas y periurbanas en la ciudad de Barcelona durante la guerra civil española, siguiendo la línea de otros trabajos que durante los últimos años han analizado la relevancia que estas prácticas tuvieron durante situaciones de crisis, particularmente conflictos bélicos, en países como Inglaterra, Estados Unidos, Alemania o la Unión Soviética. En el artículo utilizamos el concepto de agricultura urbana y periurbana, al ser esta la denominación más generalizada (Paül, 2010) y definida según la FAO como: "el cultivo de plantas y la cría de animales en el interior y en los alrededores de las ciudades». El análisis de la agricultura urbana y periurbana de Barcelona incluye un conjunto de espacios heterogéneos, que van desde fincas relativamente pequeñas, pero perfectamente insertadas en el mercado, a otras con vocación comercial combinada con autoconsumo, y hasta aquellos espacios destinados de forma única y exclusiva al autoconsumo. El caso de estudio queda delimitado por toda la actividad agrícola que se produce dentro de los límites del término municipal de Barcelona en la década de 1930 (Fig. 1). Esto incluye el llano de Barcelona y la Zona Franca, delimitados por los ríos Besós (noroeste) y Llobregat (sudoeste), la sierra de Collserola (noroeste) y la línea de costa (sudeste), donde las hortalizas tuvieron un papel preponderante durante el primer tercio del siglo $\mathrm{xx}$, un periodo considerado como los años dorados de la agricultura periurbana de la región (Paül, 2010). 
Nuestra investigación combina las fuentes primarias de distintos archivos con una revisión de la prensa del periodo y las fuentes orales. En primer lugar, hemos localizado abundante documentación sobre la Colectividad Agrícola de Barcelona y su Radio en el Arxiu Nacional de Catalunya, procedente del Centro Documental de la Memoria Histórica de Salamanca. Los principales documentos encontrados fueron la memoria de la Colectividad, correspondencia diversa y 397 certificados de trabajo pertenecientes a personas que trabajaron en la Colectividad. Además, tanto en los archivos municipales de la ciudad de Barcelona (Arxiu Municipal Contemporani de Barcelona y Arxiu Fotogràfic de Barcelona) como en el archivo privado de la empresa Aguas de Barcelona localizamos referencias de la extensión de la agricultura en la ciudad y los incidentes relacionados con ella, así como reportajes fotográficos sobre los huertos en solares urbanos y sobre las actividades de la Colectividad.

Además de las fuentes primarias de archivo, hemos revisado los boletines oficiales de la Administración pública y la prensa histórica del periodo de estudio, con especial atención a Solidaridad Obrera, ¡Campo!! (órgano del Comité de Relaciones de Campesinos, CNT-AIT), y La Vanguardia. La revisión de testimonios personales publicados (memorias y diarios) ha permitido añadir diversas referencias al recurso a la agricultura urbana y a la percepción de un cambio del paisaje de la ciudad. Por último, se ha complementado este trabajo con fuentes orales. A partir de los datos socioeconómicos extraídos de los 397 certificados de trabajo de la Colectividad hemos realizado un análisis estadístico e investigado a cada persona una por una. Esto ha permitido localizar información sobre sus vínculos con los mercados de la ciudad o las represalias sufridas al terminar la guerra, que hemos ampliado en el archivo del Tribunal Militar Territorial Tercero de Barcelona. Finalmente, mediante la búsqueda de las personas que habían trabajado en la Colectividad hemos logrado contactar con dos colectivistas todavía vivos, y entrevistar a uno de ellos. A esta entrevista se han sumado otras con personas que vivieron el periodo de la guerra civil (colaboradoras de la iniciativa Consell dels Savis, Museu d'Història de Catalunya).

La estructura del artículo es la siguiente. En la siguiente sección, situamos nuestro caso de estudio en la literatura que ha analizado el recurso a la agricultura urbana en las retaguardias durante distintos conflictos bélicos del siglo Xx. A continuación, examinamos la Colectividad Agrícola de Barcelona y su Radio, buscando sus orígenes en la militancia campesina en Barcelona antes del inicio de la guerra, y analizando su organización desde las barriadas, su desarrollo y los problemas a los que se enfrentó. En la siguiente sección, abrimos el foco para mostrar cómo la agricultura colectiva convivió con diversas tipologías de huertos que se extendieron a medida que el suministro flaqueaba y el hambre acuciaba. La ocupación de Barcelona por las tropas franquistas el 26 de enero de 1939 trajo la inmediata disolución de la Colectividad Agrícola de la ciudad, pero mu- 
chos de los huertos familiares sobrevivieron durante buena parte de la posguerra y más allá. Finalmente, en las conclusiones del artículo sintetizamos la relevancia de nuestro caso de estudio.

\section{EL RECURSO A LA AGRICULTURA URBANA EN MOMENTOS DE CRISIS}

El interés por la historia de la agricultura urbana ha surgido de forma relativamente reciente en paralelo al crecimiento y politización de estas prácticas, particularmente a partir de la década de 1980. Los periodos de depresión económica y las crisis asociadas a los conflictos bélicos han sido identificados por muchos autores como momentos de expansión de la agricultura urbana (Bassett, 1981; Lawson, 2014; Mok et al., 2014). Las guerras y las crisis económicas amenazan directamente la seguridad alimentaria, disparando los precios de materias básicas, disminuyendo su disponibilidad y causando interrupciones en los sistemas de producción, conservación, transporte y distribución de alimentos. Para afrontar esta problemática, durante la Primera y la Segunda Guerra Mundial la alimentación se concibió como parte fundamental del esfuerzo bélico, y los gobiernos contendientes desarrollaron planes para garantizar la disponibilidad y distribución de alimentos (Maltz, 2015). El fomento de la agricultura urbana en la retaguardia, habilitando espacios para el cultivo, estableciendo regulaciones y alentando a la población a labrar las tierras disponibles en las ciudades, constituyó parte de estas estrategias y proporcionó alivio a una parte significativa de la población. La propaganda presentó estos huertos como símbolos de la cooperación de la sociedad en el mantenimiento de la moral y la economía de guerra, dotándolos así de una función patriótica (Bassett, 1981; Barthel, Folke \& Colding, 2010).

Durante los últimos años, esta doble vertiente de la agricultura urbana, proveedora de alimentos y símbolo propagandístico del esfuerzo bélico en la retaguardia, ha sido estudiada en numerosos países. En esta sección examinamos los casos de algunos de los principales contendientes de las dos grandes guerras, empezando por Estados Unidos durante la Primera Guerra Mundial. La decisión de Estados Unidos de entrar en la guerra fue acompañada de la creación de una Comisión Nacional de Huertos de Guerra que lanzó una serie de carteles, libros de cocina, manuales y hasta poemas para alentar a los civiles a participar en el esfuerzo bélico mediante el cultivo de alimentos (Hayden-Smith, 2014). La retaguardia se convirtió así en un frente interior (home front) donde se combatía a través del cultivo agrícola. Esta movilización fue acompañada de una resignificación y dignificación de los huertos, tradicionalmente considerados un signo de pobreza, elevándolos a símbolo de unidad, orden y fuerza de la retaguardia (Bassett, 1981). 
En Gran Bretaña, la escasez durante la Primera Guerra Mundial fue aliviada por las importaciones de alimentos desde Estados Unidos (Maltz, 2015). No obstante, los huertos urbanos también jugaron un papel crucial en el suministro de hortalizas (Barthel, Folke \& Colding, 2010). El Gobierno promovió la campaña Every Man a Gardener («Cada hombre un horticultor») y permitió a las autoridades locales transformar los solares plantando huertos en parques y campos deportivos, e incluso en el palacio de Buckingham (Crouch \& Ward, 1988; Barthel et al., 2014). Bajo la iniciativa del Estado y en coordinación con las autoridades municipales, el número de huertos aumentó de 600.000 en 1913 a 1,5 millones en 1918. En 1918 se calculaba que los huertos urbanos habían producido dos millones de toneladas de hortalizas (House of Commons, 1998).

Después de la Primera Guerra Mundial, el número de huertos en el mundo occidental disminuyó abruptamente, si bien en algunos países la lenta recuperación económica propició el mantenimiento de estos espacios. En Austria, por ejemplo, la Liga de Colonos y Pequeños Agricultores, surgida a finales de la Primera Guerra Mundial, se expandió durante la década de 1920, y obtuvo el apoyo del gobierno socialdemócrata de la ciudad de Viena. La regulación legal de los huertos urbanos quedó integrada en las políticas de vivienda de la «Viena Roja» (O’Neill, 2003). En otros países como Suecia o Alemania, la crisis económica de la década de 1930 mantuvo la importancia de los huertos, mientras que en Estados Unidos, el Reino Unido o la Unión Soviética fue la Segunda Guerra Mundial la que provocó una nueva explosión de la agricultura urbana (Bassett, 1981; Barthel, Folke y Colding, 2010).

Probablemente, el ejemplo más recordado de la importancia de la agricultura urbana durante la Segunda Guerra Mundial es la campaña lanzada por el Gobierno británico en 1939 bajo el lema Dig forVictory! («Cava por la victoria!»). En coordinación con los municipios y las agrupaciones agrícolas locales, y con la experiencia del conflicto previo, el cultivo de la tierra se expandió por el país, convirtiéndose en un símbolo de la resistencia civil contra los bombardeos alemanes. En Londres, por ejemplo, surgieron huertos en todo tipo de espacios, desde jardines privados a parques, o incluso en los cráteres dejados por las bombas (Morán \& Hernández Aja, 2011). Este esfuerzo fue explotado por la propaganda británica mediante carteles y reportajes, pero sus resultados materiales no fueron menos significativos. En 1944 la horticultura suponía aproximadamente la mitad del consumo de frutas y verduras del país (Crouch \& Ward, 1988; Molle \& Segers, 2008).

En los países del Eje, la reivindicación de los valores de la autosuficiencia y la autarquía se conectó con el impulso a la agricultura nacional. Durante los primeros años del dominio fascista en Italia, la producción de alimentos se convirtió en un punto de orgullo nacional y una fuente de supervivencia. En Alemania, los huertos urbanos se convir- 
tieron en un símbolo ideológico, un espacio de contacto de la raza aria con la tierra. El partido Nazi impulsó la agricultura orgánica y llamó a «plantar la ideología nazi en los huertos». Tras tomar el control de las asociaciones relacionadas con la agricultura urbana, como por ejemplo la Asociación Nacional de Pequeños Huertos, con 600.000 personas afiliadas, el partido Nazi tomó medidas para que solo las personas alemanas de origen ario pudieron acceder al cultivo de un huerto (McKay, 2011; Molle \& Segers, 2008; Helstosky, 2004).

Finalmente, la reciente investigación sobre la organización de la agricultura urbana y periurbana en la Unión Soviética durante la Segunda Guerra Mundial muestra el espectacular crecimiento de esta actividad entre 1942 y 1945, un periodo durante el cual el número de personas horticultoras registradas aumentó de cinco a dieciocho millones y medio. En el más extremo contexto de escasez y guerra total, el Estado soviético promovió la horticultura de pequeña escala para la subsistencia familiar, mientras que la producción de la agricultura estatal se redirigía casi completamente a los frentes de guerra (Charon Cardona \& Markwick, 2019).

En resumen, la investigación que ha analizado el recurso a la agricultura urbana y periurbana durante los periodos de crisis se ha centrado especialmente en las guerras y ha interpretado el aumento de la importancia de los huertos urbanos y periurbanos como un ejemplo de la capacidad de resiliencia de las sociedades urbanas. Buena parte de estos trabajos se han planteado desde perspectivas interdisciplinares, con gran peso de las ciencias ambientales. En casi su totalidad, han analizado ejemplos en que la iniciativa en la promoción y expansión de la agricultura urbana fue liderada por las instituciones del Estado.

En España, sin embargo, el estudio de la agricultura urbana y periurbana durante el siglo $\mathrm{xx}$ ha recibido poca atención. En una de las más recientes y amplias publicaciones internacionales sobre la historia de la agricultura urbana en Europa, los huertos urbanos en España se conciben, a diferencia de otros países, como un fenómeno contemporáneo, que «empezó» en la década de 1980 (Keshavarz et al., 2016). De este modo, la agricultura de subsistencia en los intersticios de las ciudades queda marginalizada antes de que fuera reconvertida en política pública. En contraste con esta perspectiva, otros trabajos han destacado la importancia de las ideas urbanísticas de la ciudad jardín en España, e identificado referencias de prensa que apuntaban a proyectos para impulsar la agricultura en el Madrid de la guerra civil (Fernández Casadevante \& Morán, 2016). Asimismo, también se ha estudiado el impulso que el Instituto Nacional de Colonización dio a los huertos familiares durante las décadas de 1940 y 1950 (Gómez Herráez, 1999). Por último, desde la historia ambiental, íntimamente conectada a la historia agraria en España, se ha 
apuntado la importancia de la agricultura urbana, si bien el estudio se ha centrado en el ejemplo de Cuba a partir de la década de 1990, cuando el colapso de la Unión Soviética y el embargo comercial de Estados Unidos obligaron a la reconversión agrícola del país (Ortega, 2009; Botella-Rodríguez, 2015).

\section{CULTIVAR BAJO LAS BOMBAS: EL CASO DE BARCELONA}

\subsection{Alimentar la ciudad en guerra}

Entre 1914 y 1936, la población de Barcelona se duplicó, pasando de 600.000 a 1.200 .000 habitantes. Además de encontrar ocupación en la industria y la construcción, parte de esta nueva población de origen rural trabajó, de forma regular o temporal, en las explotaciones agrícolas que se extendían en las cercanías de los ríos Besòs y Llobregat. A pesar del rápido crecimiento urbano experimentado por Barcelona durante el primer tercio del siglo $\mathrm{xx}$, la actividad agrícola en el término municipal conservaba una gran importancia. La urbanización del Eixample había empezado a colmatar el espacio entre el núcleo histórico de la ciudad y los municipios absorbidos entre 1896 y 1921, que configuraban sus nuevos barrios. Pero el espacio dedicado a la huerta abundaba en estos, particularmente en Sant Andreu, Sant Martí y la Marina del Prat Vermell (perteneciente a Sants) ${ }^{4}$. La producción agraria del llano de Barcelona estaba especializada en hortalizas, destinadas a los mercados locales. A estas actividades agrarias se sumaban, cerca de los núcleos urbanizados, un buen número de pequeñas huertas familiares de autoconsumo, a menudo en condiciones no regularizadas. En la montaña de Montjuïc, por ejemplo, hay constancia de estos huertos desde 1910, y en 1936 se calculaba que existían al menos unos dos mil ${ }^{5}$.

Durante la década de 1930 el sostenimiento de la población de Barcelona, que junto a la de L'Hospitalet representaba en 1936 el 38\% de la población catalana, requería la importación de alimentos; especialmente trigo, pescado y carne. Aproximadamente el $45 \%$ del trigo consumido en Cataluña se compraba en Aragón, Extremadura y las dos Castillas. En este contexto, la insurrección contra la República en julio de 1936 y el control de buena parte del territorio español por parte de los insurgentes comprometió inmediatamente el abastecimiento de Cataluña. El encarecimiento de los alimentos y las pri-

4. Sobre el crecimiento urbano de Barcelona en el primer tercio del siglo xx, véase Oyón (2008). El trabajo del profesor Oyón, sin embargo, no alude a la continuidad de la actividad agrícola en los intersticios de la ciudad ni a la importancia de la agricultura familiar en el contexto urbano.

5. Montjuï, Portantveu de l'Agrupació d'Hortolans de la Muntanya de Montjüc, n. ${ }^{\circ}$ 25, febrero de 1937, pp. 11-12. Sobre los usos agrícolas de la montaña de Montjuïc, véase FABRE y HuERTAS (1976: 170-174). 
meras colas se hicieron notar ya en septiembre de 1936, y empeoraron a finales de año, cuando la falta de harina impidió durante varios días la elaboración de pan en la ciudad (Martín Ramos, 2018: 98-111, 125-135).

La cuestión de los abastecimientos se convirtió en una de las fuentes de tensión entre las organizaciones antifascistas en la retaguardia, que desembocaron en enfrentamiento abierto en Barcelona durante los Hechos de Mayo de 1937. Debido a esta conexión, el conflicto por los abastecimientos en Barcelona ha recibido una atención notable en la historiografía (véase una discusión reciente en Martín Ramos, 2018: 98-111, 125-135, 233239). Sin embargo, existe un gran contraste entre la atención prestada a la politización de los abastecimientos como detonante de la crisis de mayo de 1937, por una parte, y la falta de estudios que analicen las fuentes de suministro y las estrategias seguidas por la población para asegurar su aprovisionamiento. Si bien contamos con series de precios que permiten constatar el encarecimiento de las subsistencias (Maluquer de Motes, 2013: 7375), el estudio de las importaciones de alimentos de la Unión Soviética está por hacer (Martín Ramos, 2018: 449). De la misma manera, resulta sorprendente constatar que, en medio de la abundante literatura dedicada a las colectivizaciones agrícolas impulsadas por la Confederación Nacional del Trabajo (CNT) durante la guerra civil, la existencia de una colectividad agrícola en Barcelona con más de dos mil personas trabajadoras y casi mil hectáreas de terrenos haya pasado prácticamente desapercibida ${ }^{6}$.

A pesar del racionamiento impuesto en Barcelona a partir de marzo de 1937, el abastecimiento de los hogares se deterioró gravemente a medida que avanzaba la guerra. Las diferencias entre la producción y consumo de huevos, carne, azúcar, lentejas, garbanzos o judías secas no dejaban otra opción que intensificar las importaciones, pero a las dificultades para obtener divisas se sumaba el control que las fuerzas italianas ejercían sobre el tráfico comercial en el Mediterráneo. A la vez que la población refugiada aumentaba en la ciudad, alcanzando los 198.000 refugiados durante 1937, la producción de trigo y arroz en Cataluña disminuyó respecto del año anterior (Serrallonga i Urquidi, 2004: 190; Martín Ramos, 2018: 233-237). Ante el descenso de las cosechas de arroz, lentejas, judías y habas, el consumo de hortalizas producidas en las cercanías de la ciudad empezó

6. La Colectividad Agrícola de Barcelona es mencionada brevemente por Peirats (1971: 276). La revisión de prensa anarcosindicalista del periodo permite constatar que Peirats se limitó a resumir la información publicada en un reportaje de Solidaridad Obrera, 24 de junio de 1938, p. 2. Pese a esta mención y a la abundante literatura dedicada al estudio de las colectivizaciones agrícolas, tal y como se apunta en Gabriel (2009: 146-147), el caso de la Colectividad de Barcelona ha pasado prácticamente desapercibido. El único estudio existente sobre la colectividad es el artículo de Garcia Cazorla, Milà y Rius (1983). La exhaustiva tesis doctoral de Guillem Puig Vallverdú (2020: 208-210) recoge las referencias a la Colectividad Agrícola de Barcelona publicadas en i¡Campo!! durante 1937. 
a ocupar su lugar en la dieta de la población. El deterioro en la alimentación urbana continuó hasta el final de la guerra y más allá. La cuestión de las subsistencias fue una permanente fuente de conflicto político en la retaguardia, e iba a contribuir a la desafección de la población civil con el esfuerzo bélico hasta la entrada de las tropas franquistas en la ciudad (Martín Ramos, 2018: 233-237).

\subsection{La Colectividad Agrícola de Barcelona y su Radio}

\subsubsection{Orígenes y organización}

Al menos desde principios de la década de 1930, las personas trabajadoras del campo de la CNT en la ciudad de Barcelona estaban agrupadas en el Sindicato Único de Campesinos de Barcelona. Enraizado en los barrios, el sindicato tuvo especial presencia en los núcleos de las denominadas casas baratas, en la periferia de la ciudad, y jugó un papel clave durante la huelga de jornaleros y jornaleras de la primavera-verano de 1931 que concluyó con la aprobación de unas bases de trabajo que incluían la jornada de ocho horas y jornales de alrededor de 10 pesetas $^{7}$. Dichas bases siguieron vigentes hasta el verano de 1936, no sin conflictos. En 1933, por ejemplo, el sindicato denunciaba cómo los patronos de los campos del barrio de Sants, y en general del campo de Barcelona, vulneraban las bases con la contratación de personas de otros términos municipales por un jornal más bajo. Durante estos años el sindicato estuvo radicado en Sants y contó con unos mil afiliados y afiliadas, y participó en las elecciones a los jurados mixtos del trabajo rural. Durante las semanas previas a la insurrección militar, el Sindicato Único de Campesinos de Barcelona y su Radio organizaba encuentros con los campesinos y campesinas de la Marina del Prat Vermell, para nombrar comisiones de barriada y establecer nuevas bases de trabajo que reclamar a la patronal ${ }^{8}$.

Fue de este mismo sindicato de campesinos del cual emergió la Colectividad Agrícola de Barcelona y su Radio al inicio de la guerra civil. Durante las primeras semanas de la guerra, las personas del sindicato residentes en los grupos de casas baratas Milans del Bosch (en la orilla del río Besòs) y Eduardo Aunós (en la Marina del Prat Vermell) incautaron las tierras que trabajaban, así como otras que habían quedado abandonadas (Ga-

7. LaVoz de Asturias, 26 de junio de 1931, p. 2; Solidaridad Obrera, 28 de junio de 1931, p. 10. Sobre los orígenes del Sindicato, véase también ANC, ANC1-886-T-13819, "Memoria de la Colectividad Agrícola de Barcelona y su Radio", septiembre de 1938. Sobre las casas baratas como núcleos de militancia de la CNT, véase EALHAM (2005: 6-8, 22, 77, 93, 101-103, 110).

8. Solidaridad Obrera, 19 de junio de 1936, p. 6. 
llardo \& Márquez Rodríguez, 1997: 173; López Sánchez, 2013: 233-234). A principios de agosto de 1936, el Boletín de Información de la CNT anunciaba que el Comité de Barriada de Les Corts había empezado a cultivar en régimen colectivo los campos y huertos que había en los conventos requisados en la zona ${ }^{9}$. Semanas después, en las páginas de Solidaridad Obrera, uno de los miembros de este comité llamaba a los campesinos de Barcelona a seguir el ejemplo de Les Corts en el resto de los barrios, incautando y empezando a cultivar las tierras disponibles en la ciudad ${ }^{10}$. Finalmente, el 8 de octubre de 1936 los campesinos y campesinas del barrio de Sants, que incluían a los de la Marina del Prat Vermell, anunciaban en la prensa anarcosindicalista su transformación en colectividad y animaban a unirse a ella ${ }^{11}$. Durante las siguientes semanas se fraguó la unión de las distintas barriadas de Barcelona, acordada finalmente el día 9 de diciembre de 1936, fecha de nacimiento de la Colectividad Agrícola de Barcelona y su Radio ${ }^{12}$. Esta tardía fecha de formación explica que esta colectividad no quedara recogida en la encuesta sobre colectivización de la tierra que la Generalitat de Catalunya concluyó ese mismo mes (Garcia Cazorla, Milà \& Rius, 1983).

La Colectividad Agrícola de Barcelona y su Radio agrupó inicialmente un total de seis barriadas: Horta, Sarrià, Pla Martí (Sant Martí), Armonía del Palomar (Sant Andreu), Sants y Gramenet de Besòs (Santa Coloma de Gramenet) ${ }^{13}$. Esta última se escindió a mediados de 1937 y se constituyó como colectividad independiente ${ }^{14}$. A partir de las organizaciones de las distintas barriadas de Barcelona se formó un Consejo Central de Empresa, asesorado por comisiones de barriada, formadas por personas trabajadoras y antiguos patronos. Cada barriada fue dividida en zonas y cada zona en grupos, formados por unos veinticinco obreros y obreras, y encabezados por un delegado técnico ${ }^{15}$. La Colectividad de Barcelona se integró en la sección de campesinos del Sindicato de las Industrias Agrícolas, Pesca y Alimentación de la $\mathrm{CNT}^{16}$. De acuerdo con su documenta-

9. La nota fue reproducida en La Vanguardia, 9 de agosto de 1936, p. 7.

10. Paulino Sosa, «La nueva estructuración económica: Las barriadas de Barcelona en la agricultura", Solidaridad Obrera, 8 de septiembre de 1936, p. 14.

11. Solidaridad Obrera, 7 de octubre de 1936, p. 13.

12. ANC, ANC1-886-T-13819, "Memoria de la Colectividad Agrícola de Barcelona y su Radio», septiembre de 1938. Dos reportajes sobre la colectividad publicados en iiCampo!! ofrecen otras fechas: el 8 de septiembre de 1936 y octubre de 1936 (tras el Pleno Regional de Campesinos de Cataluña). Véanse, respectivamente, iiCampo!!, 12 de junio de 1937, p. 8, y 6 de noviembre de 1937, p. 4.

13. Los cambios de nombre municipales afectaron principalmente a localidades con nombres relacionados con el santoral, instituciones eclesiásticas o de la realeza (TORT, 2003).

14. ¡Campo!!, 13 de noviembre de 1937, p. 4.

15. ANC, ANC1-886-T-13819, "Memoria de la Colectividad Agrícola de Barcelona y su Radio», septiembre de 1938 . 
ción interna, sus inicios estuvieron lastrados por la falta de medios económicos para cubrir primeras necesidades, como la adquisición de semillas, abonos o maquinaria agrícola. Estas dificultades se solucionaron gracias a los préstamos de antiguos patronos y a las retenciones semanales en los salarios de los trabajadores y trabajadoras de la Colectividad, que posteriormente fueron devueltos ${ }^{17}$.

Durante el año 1937 el número de personas que trabajaban en la Colectividad aumentó rápidamente, pasando de 1.200 a finales de 1936 a un máximo de 3.500 en junio de 1937 e incluyendo unas quinientas mujeres ${ }^{18}$. Este crecimiento absorbió a personas sin empleo de origen rural con conocimientos agrarios previos, así como a refugiados y refugiadas de guerra, seiscientos de los cuales fueron acogidos por la Colectividad ${ }^{19}$. Sin embargo, la marcha de los trabajadores llamados a filas, en particular de aquellos especializados y conocedores de la agricultura local, supuso un grave problema ${ }^{20}$. Las necesidades de la Colectividad se trataron de suplir mediante el funcionamiento de una bolsa general de trabajadores y trabajadoras ${ }^{21}$. En septiembre de 1938, el total de personas empleadas se había reducido a 1.650 fijas y 865 eventuales. El análisis de 397 certificados de las personas trabajadoras de la Colectividad (una muestra del 15,79\% del total de trabajadores y trabajadoras en estas fechas) muestra que el rango de edad oscilaba entre los 14 y los 64 años, pero el $70 \%$ se encontraba entre los $40-49$ años. Si observamos los porcentajes diferenciados entre hombres y mujeres, vemos que abundaban las mujeres de 20 a 49 años y los hombres de 40 a 59 años, mientras que la franja masculina situada entre los 20 y 40 años era inexistente. El salario más común entre los hombres era de 180 pesetas por semana, mientras que el de las mujeres y los niños era de 115 pesetas por semana. Las personas trabajadoras vivían en vecindarios de toda Barcelona, con una especial concentración en los núcleos de las casas baratas ${ }^{22}$.

16. iCampo!!, 12 de junio de 1937, p. 8.

17. ANC, ANC1-886-T-13819, «Memoria de la Colectividad Agrícola de Barcelona y su Radio», septiembre de 1938; ANC, ANC1-886-T-13817, «Informes sobre la organización de la distribución de la producción y sobre afiliados, tabla de coeficientes", no datado: posterior al 4 de marzo de 1937.

18. ¡Campo!!', 12 de junio de 1937, p. 8.

19. Solidaridad Obrera, 24 de junio de 1938, p. 2.

20. ANC, ANC1-886-T-13819, "Memoria de la Colectividad Agrícola de Barcelona y su Radio», septiembre de 1938. Esta cuestión afectaba a numerosas colectividades y fue tratada en el Comité Regional de Campesinos de junio de 1937, donde se pidió el retorno del frente de los campesinos especializados en el cultivo (GAVALDA, 2016: 179).

21. ANC, ANC1-886-T-13819, "Cartas con sindicatos de CNT y con comisiones de barriadas relativas a trabajadores", abril a junio de 1938.

22. Datos elaborados a partir de los certificados de trabajo de la Colectividad Agrícola de Barcelona y su Radio (ANC, ANC1-1-T-9316). Entrevista con Ángel Sacristán, miembro de la Colectividad Agrícola de Barcelona y su Radio en la masía Can Casas (Marina del Prat Vermell), 11 de febrero de 2020. 


\subsubsection{Producción y distribución}

Los informes internos de la Colectividad Agrícola de Barcelona y su Radio durante el verano de 1938 ofrecen una síntesis de las zonas de cultivo que manejaba y sus características en sus distintos barrios (Tabla 1). De acuerdo con estos datos, de un total de 851 hectáreas cultivadas por la Colectividad más del $50 \%$ se encontraban en el barrio de Sants y la Marina del Prat Vermell $(462,48$ ha) y casi una cuarta parte en Armonía del Palomar (202,77 ha), las principales zonas agrícolas del término municipal. Las restantes hectáreas se dividían entre Pla Martí (123,05 ha), el barrio de Horta (35,26 ha) y el de Sarrià $(28 \mathrm{ha})^{23}$. Entre la tipología de terrenos ocupados por la Colectividad se incluían fincas incautadas a terratenientes, así como aquellas pertenecientes a distintos conventos y monasterios. A estas se sumaban las de pequeños propietarios que se habían unido a la Colectividad y otras fincas que se encontraban sin cultivar antes de la guerra ${ }^{24}$. Si bien no hay constancia de que se lograra la colectivización de todas las tierras del municipio, como sí ocurrió en L'Hospitalet de Llobregat o el Prat de Llobregat (Balcells, 2017: 86), la Colectividad se convirtió indudablemente en la principal empresa agrícola de la ciudad.

En 1936 Barcelona disponía de un total de dieciséis mercados cubiertos de venta al por menor y dos de venta al por mayor (Miller, 2010: 299). La Colectividad se encargaba de la distribución y venta directa de sus productos en los 105 puestos de venta al público de los que disponía en estos mercados y señalaba que la supresión de intermediarios había permitido mejorar los precios ${ }^{25}$. A los puestos de venta en los mercados municipales se sumaban quince más en las zonas de cultivo, destinados a la distribución de verduras únicamente entre los trabajadores y trabajadoras de la Colectividad y sus familias, que recibían un racionamiento adicional al oficial ${ }^{26}$. La principal producción de la Colectividad fueron las hortalizas, calculadas aproximadamente en 36.000 toneladas anuales. Este valor, de acuerdo con estos informes, representaba el $90 \%$ de las verduras distribuidas en los mercados de la ciudad. Asimismo, la cosecha de patatas de la Colectividad durante

23. ANC, ANC1-886-T-13819, "Memoria de la Colectividad Agrícola de Barcelona y su Radio», septiembre de 1938.

24. De acuerdo con iiCampo!!, 6 de noviembre de 1937, p. 4, algunas de estos espacios eran la finca Ganduxer en Sarrià, la finca de la viuda de Miralles en Vallvidrera o la finca del antiguo conde de Güell en Pedralbes. También se mencionaban los conventos de San Pedro, Descalzos, Loreto, Reparadoras y Jerónimas en Sarrià, y el convento de Oblatas en Bonanova.

25. ANC, ANC1-886-T-13819, "Memoria de la Colectividad Agrícola de Barcelona y su Radio», septiembre de 1938.

26. ANC, ANC1-886-T-13819, «Informe sobre la distribución de verduras entre los trabajadores». Barcelona, 20 de diciembre de 1938. 
el año 1938 ascendió a 2.459 toneladas, cuyo $15 \%$ se distribuyó a hospitales e intendencia militar, el 30\% a las personas de la Colectividad, y el 55\% restante en los mercados de la ciudad. La documentación no aporta datos cuantitativos sobre la producción del resto de los cultivos, pero apunta que las ventas de verdura, patatas, maíz y cereales en el ejercicio 1937-1938 alcanzaron un valor total de 25 millones de pesetas ${ }^{27}$.

TABLA 1

Barcelona, septiembre de 1938: Inventario de material y personal según barriadas

\begin{tabular}{lrrrrrr}
\hline BARRIADAS & Pla Martí & Sants & Armonía & Horta & Sarrià & TOTAL \\
\hline Hectáreas de terreno & 202,77 & 462,48 & 123,05 & 35,26 & 28 & 851,5 \\
Caballerías de tiro & 106 & 150 & 33 & 10 & 9 & 308 \\
Carros y camiones & 198 & 170 & 55 & 17 & 12 & 452 \\
Grupos motores y bombas & 44 & 20 & 8 & 21 & 11 & 104 \\
Arados y cultivadores tipo planet & 218 & 179 & 74 & 10 & 7 & 488 \\
Herramientas manuales & 1880 & 1320 & 340 & 150 & 98 & 3788 \\
Obreros colectivos & 560 & 650 & 270 & 90 & 80 & 1650 \\
Obreros eventuales & 400 & 300 & 110 & 35 & 20 & 865 \\
\hline
\end{tabular}

Fuente: ANC, ANC1-886-T-13819, «Memoria de la Colectividad Agrícola de Barcelona y su Radio», septiembre de 1938.

Con la finalidad de aumentar el rendimiento productivo de sus terrenos, la Colectividad utilizó parte de sus ingresos para impulsar la instalación de motobombas y extender el regadío (Tabla 1), y organizó el cultivo en función de las características de los terrenos de las distintas barriadas. En Pla Martí y Armonía del Palomar, dadas las buenas condiciones para el regadío y la fertilidad de la tierra, se cultivaron exclusivamente hortalizas. Sarrià y Horta, tierras más elevadas, se dedicaron a los árboles frutales y al cultivo de verduras. Finalmente, en las zonas más elevadas de Sants se cultivaron hortalizas, mientras que algunas zonas de llano de la Marina del Prat Vermell se dedicaban a los piensos para la caballería de tiro (Tabla 1), fundamentales para el transporte de la producción a los mer$\operatorname{cados}^{28}$. A finales de abril de 1937 en Barcelona aumentó el número de vacas debido a

27. De acuerdo con la memoria de la colectividad elaborada durante el verano de 1938, la producción bajo el régimen de gestión colectivo había aumentado un $30 \%$. Sin embargo, los datos de producción de verduras fueron considerados bajos por los representantes de la Liga Nacional Campesina "Úrsulo Galván», en relación con el número de trabajadores y trabajadoras y el resto de los recursos de la colectividad. ANC, ANC1-886-T-13819, «Memoria de la Colectividad Agrícola de Barcelona y su Radio", septiembre de 1938; ANC, ANC1-886-T-13810, "Cartas con afiliados e instituciones sobre diversos asuntos", oficio con fecha 22 de noviembre de 1938.

28. ANC, ANC1-886-T-13819, "Memoria de la Colectividad Agraria de Barcelona y su Radio», septiembre de 1938. Según las informaciones que la Colectividad ofreció a la prensa, los principales cultivos de verano eran las patatas, las coles, los tomates, los pimientos, las judías y los cereales; mien- 
una mayor facilidad de obtención de forrajes y con una alta demanda causada en parte por el incremento de población hospitalizada y exiliada ${ }^{29}$. Sin embargo, pasado un año, durante el verano de 1938, la escasez de piensos y la pérdida de animales de carga era una de las grandes preocupaciones de la Colectividad, junto a la escasez de semillas y los repetidos asaltos que sufrían en sus huertos ${ }^{30}$. Pese a estas dificultades, los ingresos de la Colectividad permitieron pagar los salarios de sus trabajadores y trabajadoras y mejorar sus condiciones laborales, incluyendo subsidios por enfermedad y seguro médico. También se invirtió en nuevas herramientas y calzado adecuado, así como en mejoras sanitarias, como la instalación de duchas cerca de las zonas de trabajo. Por último, la Colectividad apoyó económicamente a la población refugiada, así como a diversos hospitales, clínicas y al periódico Solidaridad Obrera. La intensificación de los bombardeos en la ciudad trajo consigo dificultades añadidas a la Colectividad, como perder a colectivistas a causa de las bombas, con la consiguiente asistencia económica a sus familias ${ }^{31}$.

Si bien la posición de la Colectividad en la prensa anarcosindicalista destacó que los antiguos patrones y los pequeños propietarios se habían unido a la Colectividad voluntariamente y sin incidentes, la documentación disponible muestra que a medida que avanzaba la guerra algunos de ellos fueron solicitando abandonarla. De hecho, de las 2.500 mojadas de tierra que la Colectividad afirmaba cultivar en 1937 (aproximadamente $1.224 \mathrm{ha}$ ), se pasó a una superficie de 851,5 hectáreas en el verano de 1938, lo que suponía una reducción de más de un $30 \%{ }^{32}$. La escisión de la Colectividad de Gramenet, que contaba apenas con cuarenta hectáreas de tierras, no explica esta significativa disminución. Esta puede interpretarse en el marco de las reformas impulsadas por el Departamento de Agricultura de la Generalitat de Catalunya durante 1937, que reafirmaron el poder de la Administración sobre las tierras incautadas por las colectividades e impulsaron el desarrollo de las explotaciones familiares mediante la aprobación de varios decretos y el establecimiento de las juntas agrarias municipales. $\mathrm{Al}$ amparo de esta legis-

tras que los cultivos de invierno eran brócolis, escarolas, acelgas, lechugas, alcachofas, habas y guisantes (iCampo!!, 6 de noviembre de 1937, p. 4).

29. P.Vila, «Un problema del camp i de la ciutat: La qüestió de la llet», La Publicitat, 25 de abril de 1937, p. 3.

30. ANC, ANC1-886-T-13814, «Informe sobre la Colectividad Agrícola de Barcelona y su Radio», 15 de agosto de 1938.

31. ANC, ANC1-886-T-13819, "Memoria de la Colectividad Agrícola de Barcelona y su Radio», septiembre de 1938; ANC, ANC1-886-T-13810, "Cartas con afiliados e instituciones sobre diversos asuntos", 6 de noviembre de 1937 a 14 de enero de 1939; ANC, ANC1-886-T-13803, "Actas de reuniones». junio y septiembre de 1938.

32. Estas cifras proceden, respectivamente, del reportaje publicado en iiCampo!!, 6 de noviembre de 1937, p. 4, y ANC, ANC1-886-T-13819, «Memoria de la Colectividad Agrícola de Barcelona y su Radio", septiembre de 1938. 
lación, tal y como ocurrió en otros municipios vecinos, pequeños propietarios que se habían unido inicialmente a las respectivas colectividades reclamaron su salida y la recuperación de sus tierras (Santacana, 1989: 514-515). Un ejemplo de este proceso en el municipio barcelonés es la reclamación del antiguo arrendador de las tierras de la finca de Can Barreta, en el barrio de Horta, que en 1938 solicitó que la Colectividad le devolviera sus tierras, animales, carro y herramientas, así como que le abonaran posibles perjuicios. La Junta Municipal Agraria de Barcelona resolvió a su favor. La documentación conservada incluye referencias a otros casos similares ${ }^{33}$.

\subsection{Agricultura urbana de autoconsumo}

\subsubsection{Tipologías de la agricultura de subsistencia}

A mediados de la década de 1930 cientos de huertos familiares poblaban la geografía de Barcelona. A los dos mil huertos asociados a la Agrupació d'Hortolans de la Muntanya de Montjuïc, se sumaban más de diez mil huertos en el resto de la ciudad ${ }^{34}$. Durante el otoño de 1936, la Colectividad Agrícola de Barcelona y su Radio ocupó mayoritariamente los espacios periurbanos de la ciudad, pero respetó la actividad agrícola realizada a título individual o familiar, siempre que no hubiera personas asalariadas ni arrendamientos ${ }^{35}$.

Sin embargo, cuando el deterioro del suministro alimentario de Barcelona obligó a establecer el racionamiento y empezó a poner en jaque la capacidad de aprovisionamiento, un creciente número de familias se lanzó a cultivar su propio huerto, sin tener necesariamente relación con la Colectividad. Los testimonios e historias de vida del periodo han dejado muestras de una percepción de cambio del paisaje urbano, donde las hortalizas se empiezan a abrir paso en cualquier parterre, jardín o espacio abandonado ${ }^{36}$. Si bien algunos de estos nuevos agricultores y agricultoras se tomaron la molestia de solicitar per-

33. ANC, ANC1-886-T-13810, "Cartas con afiliados e instituciones sobre diversos asuntos», 6 de noviembre de 1937 a 14 de enero de 1939.

34. AMCB, exp. n. ${ }^{\circ}$ GM-895, cód. A183 Comissió de Governació, «Petició de l'Agrupació de Montjuïch referent al Decret de la Generalitat de 10 d'agost de 1938 i el tribut sobre la terra dels horts familiars".

35. Así lo afirmaban en iiCampo!!, 12 de junio de 1937, p. 8. Basándose en un acuerdo aprobado en septiembre de 1936, la CNT respetó este tipo de explotaciones (BALCELls, 2017: 86).

36. Entrevistas Museu d'Història de Catalunya (MHCAT). Roser Rosés Senabre y Concepció Cortés Lara, Barcelona, 21 de enero de 2019, y Antoni Verdú, Barcelona, 4 de febrero de 2019. Véanse también diarios personales y testimonios sobre la vida cotidiana durante la guerra (MARTORELL I GIL \& DOMĖNeCh i DOMĖNech, 2008: 30; SERRA \& SERRA, 2003: 230). 
misos al Ayuntamiento, en la mayor parte de los casos estas ocupaciones se dieron de forma irregular ${ }^{37}$. Aunque no hay constancia de que estos huertos estuvieran integrados en la Colectividad Agrícola de Barcelona, el florecimiento de la agricultura en los márgenes de la ciudad y la ocupación de espacios simbólicamente asociados a la burguesía, como el Turó Park, fueron recibidos positivamente en la prensa anarcosindicalista (Fig. 2). La aportación de estos pequeños huertos era loada como una "economía minúscula» que, en conjunto, lograba un resultado relevante y tangible, aunque «no figurará en las tablas de las gráficas oficiales» ${ }^{38}$. Sin embargo, no faltaron las voces que advertían contra el «espíritu tenderil» y las «intenciones bastardas del materialismo» de las personas dedicadas a la agricultura urbana ${ }^{39}$.

Los huertos se extendieron también a fábricas y escuelas. Algunas empresas colectivizadas distribuyeron pequeñas fincas entre sus trabajadores y trabajadoras para usarlas como huertos (Domènech, 2012: 135), mientras que en grandes empresas como la Maquinista Terrestre y Marítima los propios obreros y obreras organizaron un huerto y pagaron conjuntamente un vigilante ${ }^{40}$. En numerosos proyectos escolares, la dimensión educativa de los huertos se combinó con su función para el aprovisionamiento, en la línea de renovación y mayor contacto con la naturaleza propugnada por el nuevo Consell de l'Escola Nova Unificada (Masjuan, 2000: 195-202). En el barrio de Horta, el Ayuntamiento de Barcelona estableció una escuela productiva donde los alumnos y alumnas cuidaban del huerto y se ocupaban de la venta de sus productos ${ }^{41}$. La casa y los grandes jardines del director de la empresa Aguas de Barcelona fueron incautados por los trabajadores y trabajadoras de la CNT y convertidos en el Grup Escolar Ferrer i Guàrdia, donde cada clase cuidaba de su propio huerto ${ }^{42}$.Y en el barrio de Pedralbes, un grupo de jóvenes refugiados y refugiadas de Madrid levantó las pistas de tenis de la mansión incautada que les acogía para empezar a cultivar un huerto ${ }^{43}$. Además de formar parte de su educación y alimentación, los huertos escolares, así como los iniciados en casas de acogida para jóvenes refugiados y refugiadas, adquirieron una dimensión simbólica y propagandística

37. Véase, por ejemplo, AMCB, exp. n. ${ }^{\circ}$ N-2763, cód. Q137 Eixample, «Demanda per al cultiu de terrenys sense edificar del c. de Jaume Cancer».

38. "Trabajo loable: La minúscula economía», Solidaridad Obrera, 1 de junio de 1938, p. 1.

39. «Pla de Besòs», Solidaridad Obrera, 9 de diciembre de 1937, p. 7.

40. Véase el sumario n. ${ }^{\circ} 15.048$ contra Ángel Nicolás Oliva, en el archivo del Tribunal Militar Territorial Tercero de Barcelona.

41. "Grupo de Ensayo de Escuela Productiva», „¡Campo!!, 23 de octubre de 1937, pp. 2 y 6.

42. Mundo Gráfico, 3 de marzo de 1937, p. 8; Luz y Fuerza, n. ${ }^{\circ}$ 5, abril de 1937, p. 5. Véase también Wendenburg (2010).

43. La Vanguardia, 20 de mayo de 1937, suplemento gráfico, p. 2; La Vanguardia, suplemento gráfico, 6 de enero de 1938, p. 4. 
como metáforas de la revolución y de la lucha de la República contra las tropas franquistas (Fig. 3).

\section{FIGURA 2}

«Cataluña: El amor a la tierra», reportaje con montaje fotográfico de los huertos en Turó Park (Barcelona), a partir de fotografías de Pérez de Rozas ${ }^{44}$

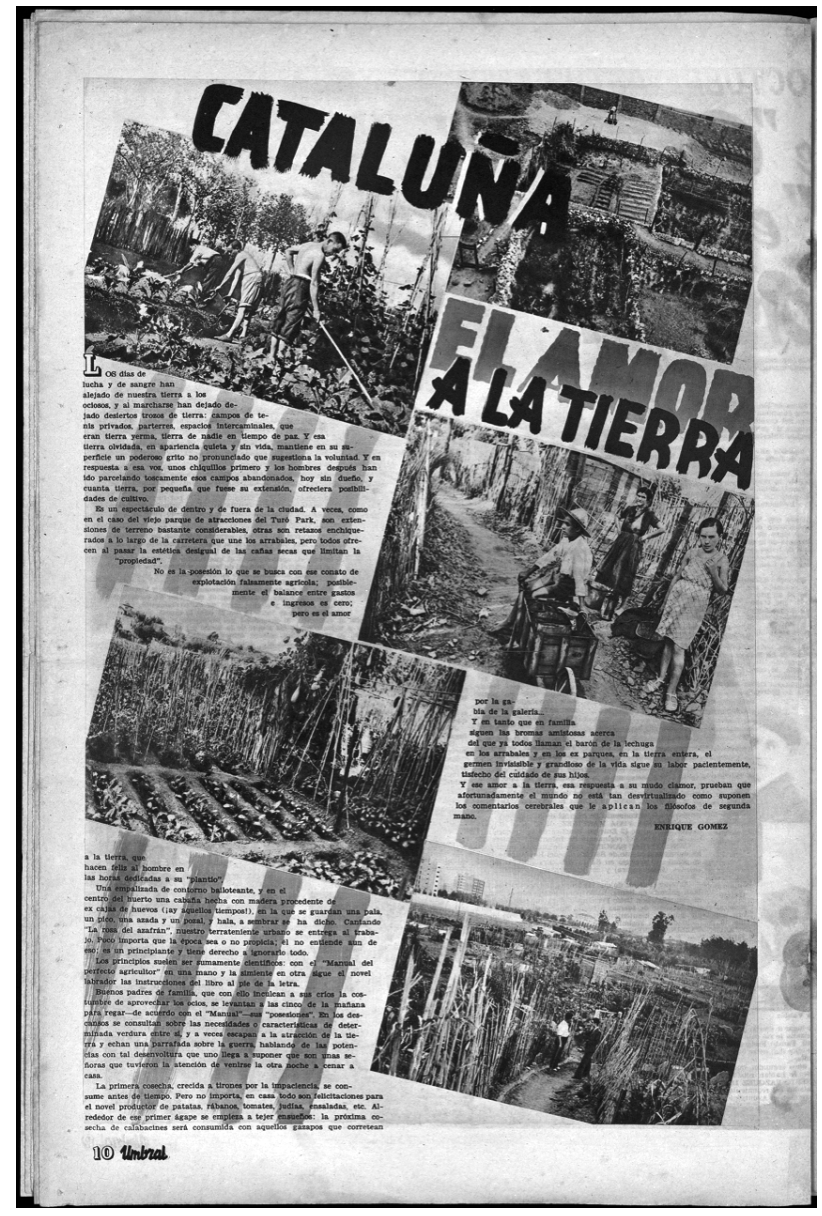

Fuente: Umbral, n. ${ }^{\circ}$ 15, 23 de octubre de 1937, p. 10.

44. Los originales de estas fotografías se conservan en el Arxiu Fotogràfic de Barcelona, signaturas topográficas C1_005_084_01 a C1_005_084_10, 16 de septiembre de 1937. 


\section{FIGURA 3}

«Pequeños refugiados madrileños», montaje fotográfico del huerto cultivado por jóvenes madrileños en una casa del barrio de Pedralbes (Barcelona), a partir de fotografías de Antoni Campañá

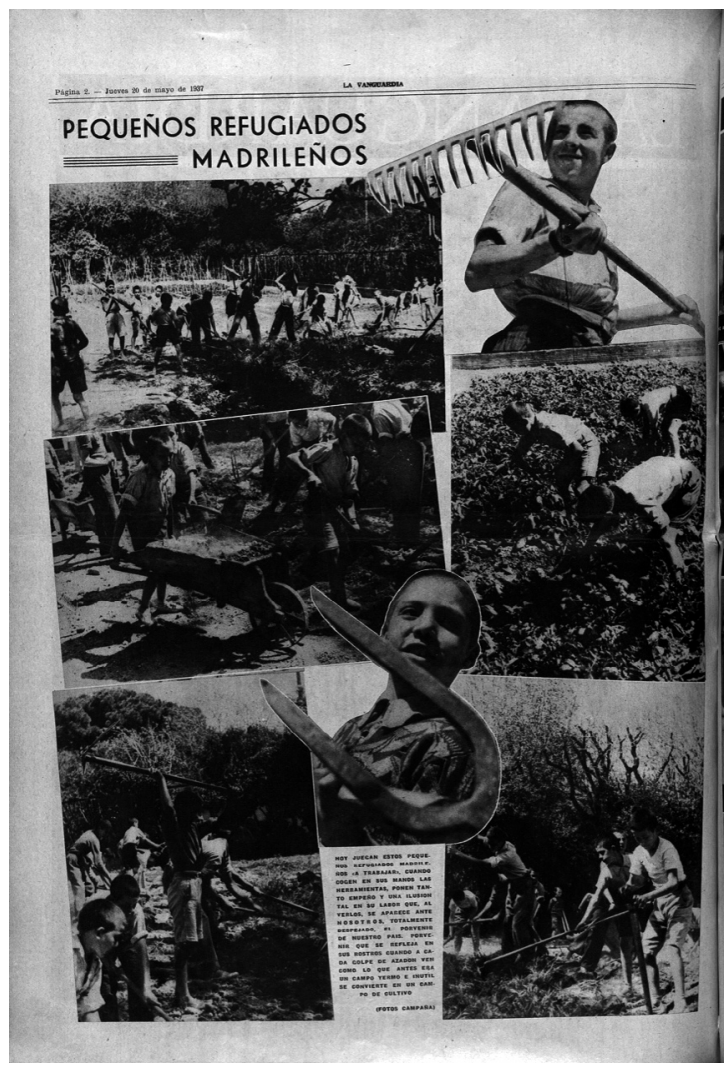

Fuente: La Vanguardia, 20 de mayo de 1937, suplemento gráfico, p. 2.

La extensión de los huertos, y especialmente del riego asociado a ellos en distintos puntos de la ciudad, se hizo sentir en las oficinas de la empresa colectivizada Aguas de Barcelona, responsable del suministro de agua urbano (Gorostiza, March \& Sauri, 2013: 918; Gorostiza, 2019: 36). A principios de julio de 1937, la empresa detectó un aumento del uso de la red de suministro para regar los huertos, y solicitó a la Conselleria de Serveis Públics del Ayuntamiento que intensificara el control sobre tuberías y bocas de riego ${ }^{45}$. En pleno agosto de 1937, Aguas de Barcelona Empresa Colectivizada publicó un anun-

45. Arxiu General d'Aigües de Barcelona (AGAB), caja 7374, "Carta de Aguas de Barcelona Empresa Colectivizada al Regidor de la Conselleria de Serveis Públics de l'Ajuntament de Barcelona», 
cio advirtiendo de que denunciaría a aquellas personas que captaran el agua de la red de suministro de forma fraudulenta ${ }^{46}$. El goteo de quejas recibidas por la empresa indica que, lejos de reducirse, el uso subrepticio de la red de suministro de la empresa para el riego siguió aumentando. En abril de 1938, el Ayuntamiento de Barcelona acordó poner guardias en las fuentes para evitar los abusos destinados al riego de pequeños huertos, mientras que la Generalitat publicó una orden para restringir el consumo de agua y reducir el uso para el riego (Generalitat de Catalunya, 1938a) ${ }^{47}$. Durante 1938 las denuncias de clientes de Aguas de Barcelona a vecinos y vecinas que abusaban del agua para regar sus huertos se multiplicaron ${ }^{48}$. Según afirmaban los responsables de la empresa colectivizada en agosto de 1938, el desarrollo de los huertos urbanos y los pinchazos en la red de suministro de agua habían alcanzado tales cotas que reducían la presión del resto del sistema ${ }^{49}$. En conjunto, mientras que el consumo de electricidad en la ciudad se hundió (Bricall, 1970: 47-55), la extracción de agua de los pozos de la empresa en Cornellà no dejó de aumentar durante toda la guerra (Ferret i Pujol, 1985: 27).

\subsubsection{El decreto de regulación de huertos de la Generalitat de Catalunya}

El 25 de julio de 1938 el ejército republicano cruzaba el río Ebro; con ello se iniciaba la última gran batalla de la guerra civil española. Mientras tanto, Barcelona acogía ya a 318.000 personas refugiadas, y la expansión de los huertos familiares ocupaba a todo tipo de personas y espacios, desde el patio de la cárcel de mujeres hasta el jardín del director de la Biblioteca de Catalunya (Serrallonga i Urquidi, 2004: 190; Domènech, 2012: 134135, 144, 159-160). En este contexto, el 10 de agosto de 1938 la Generalitat de Catalunya aprobó un decreto destinado a la regulación del uso de terrenos viales, solares y tierras yermas y su transformación en huertos familiares (Generalitat de Catalunya, 1938b). Dicho decreto establecía que las personas interesadas en cultivar huertos para uso personal o familiar en tierras que no fueran de su propiedad deberían solicitarlo a su ayuntamiento. La superficie máxima de los terrenos a cultivar sería de 150 metros cuadrados y en ningún caso se podría disponer de más de un huerto ni comercializar los productos obtenidos $^{50}$.

46. La Vanguardia, 19 de agosto de 1937, p. 2.

47. AMCB, «Llibre 400 de les actes municipals», 6 de abril de 1938.

48. Véanse, por ejemplo, varias denuncias recibidas por Aguas de Barcelona Empresa Colectivizada con fechas 3 de julio, 18 de julio y 31 de julio de 1938, en AGAB, caja 7377.

49. AGAB, caja 7378, "Carta de Aguas de Barcelona Empresa Colectivizada al Cap de l'Oficina d'Assistència Social", 4 de agosto de 1938.

50. Gaseta municipal de Barcelona, año 025, núms. 38-41 (19, 26 de septiembre, 3, 10 de octubre de 1938), p. 212. 
Además de establecer las condiciones para ocupar un espacio y dedicarlo a la agricultura familiar, el decreto de la Generalitat daba un plazo de treinta días para regularizar aquellos espacios que se usaban como huertos familiares desde el 19 de julio de 1936, bajo pena de quedar privados de continuar con sus trabajos. Esto fue recibido con preocupación por diversos grupos que cultivaban tierras de forma irregular. La Agrupació d'Hortolans de la Muntanya de Montjuïc ofreció al Ayuntamiento de Barcelona regular la situación de sus huertos a cambio de un impuesto reducido ${ }^{51}$. Asimismo, la sección de Horticultura del Sindicato de Industrias Alimenticias (CNT) convocó a sus personas afiliadas a una reunión para informar de los detalles del decreto ${ }^{52}$. Probablemente este fuera el origen de la Agrupación Cooperativa de Pequeños Hortelanos (CNT), que incluyó a numerosos agricultores y agricultoras cuyos pequeños huertos no formaban parte de la Colectividad Agrícola de Barcelona y su Radio ${ }^{53}$.

$\mathrm{Al}$ decreto sobre regulación de los huertos familiares se le sumaron durante los siguientes meses dos órdenes de la Conselleria d'Agricultura, destinadas a promover el cultivo de las tierras abandonadas abriéndolo a los miles de personas refugiadas llegadas a Cataluña y priorizando aquellas peticiones provenientes de personas con conocimientos de agricultura (Generalitat de Catalunya, 1938c, 1938d). La Conselleria d'Agricultura mostró interés en las posibilidades de la agricultura familiar, y encargó un estudio para analizar su importancia en el municipio de Roses de Llobregat (Sant Feliu de Llobregat), muy cercano a Barcelona. Parte de los resultados de este se publicaron en 1938 en la revista de l'Escola Superior d'Agricultura, bajo el título «El conreu de la terra com a ocupació secundària dels no agricultors». Sus autores centraban el estudio en aquellos trabajadores que no se dedicaban a la agricultura de manera profesional. En un detallado análisis de la agricultura urbana y periurbana de Roses de Llobregat, determinaban que casi un tercio de la población $(29,4 \%)$ se dedicaba a esta actividad, lo que confirmaba que trabajadores dedicados a todo tipo de profesiones habían empezado a trabajar la tierra y lograr así parte de su sostén. Los autores del estudio apuntaban que el contexto bélico y de escasez había dado una «importancia insospechada» a la cuestión de la agricultura familiar entre los agricultores no profesionales (Llovet \& Riu, 1938).

51. AMCB, exp. n. ${ }^{\circ}$ GM-895, cód. A183 Comissió de Governació, «Petició de l'Agrupació de Montjuïch referent al Decret de la Generalitat de 10 d'agost de 1938 i el tribut sobre la terra dels horts familiars".

52. La Vanguardia, 10 de septiembre de 1938, p. 4.

53. Centro Documental de la Memoria Histórica de Salamanca (CDMH), CNT. Agrupación Cooperativa de Pequeños Hortelanos, Fichas de afiliados, ES.37274.CDMH/PS-BARCELONA,911,1, 1938. 


\subsection{Derrota}

El esfuerzo humano, militar y de aprovisionamiento en la batalla del Ebro dejó exhausta a la Cataluña republicana. En su capital, la escasez en el abastecimiento alimentario se agravó dramáticamente. Desde los primeros meses de la guerra, la proximidad de los cultivos urbanos y periurbanos a las viviendas de la ciudad, castigada por el hambre en mayor medida que las zonas rurales, había propiciado episodios de robos. Pero a medida que avanzó la guerra, estos se convirtieron en una de las principales dificultades para la Colectividad Agrícola. Un informe interno fechado en agosto de 1938 afirmaba que los campos de la Colectividad eran "constantemente asaltados", lo que suponía unas pérdidas diarias de 40 toneladas de verduras, puesto que a los robos se sumaba la verdura que debía recogerse antes de que estuviera madura. A su vez, la pérdida de las plantas madre comprometía la capacidad de la Colectividad de proveerse de semillas ${ }^{54}$. Para afrontar esta situación, la Colectividad firmó en septiembre de 1938 un acuerdo con el Departamento Administrativo de Guardias Rurales y Forestales de Cataluña, que pasaron a encargarse de la vigilancia de los campos a cambio de adquirir los mismos derechos que el resto de las personas pertenecientes a la Colectividad ${ }^{55}$. En las semanas inmediatamente previas a la ocupación de Barcelona por las tropas franquistas, los guardas reportaron la incautación de verduras a diversas personas de la propia Colectividad, que admitían los robos y declaraban no tener suficiente para comer. Los robos fueron motivo de suspensión de empleo e incluso de expulsión, como medida ejemplarizante para el resto de los colectivistas ${ }^{56}$.

Los guardias de la Colectividad se vieron obligados a afrontar asaltos de grandes grupos organizados, en ocasiones con consecuencias trágicas. Durante el mes de julio de 1938, dos asaltos a los campos de la Marina del Prat Vermell terminaron con la muerte de un niño y un joven de 18 años (López Sánchez, 2013: 272-274). En Bon Pastor, la muerte de una joven, aparentemente relacionada con el asalto de los campos de la Colectividad, dio lugar a una sentencia de muerte para uno de sus dirigentes durante los primeros meses de la posguerra. Este no fue el único caso de represión de las personas de la Colectividad que se quedaron en Barcelona, algunas de las cuales fueron arrestadas y juzgadas por rebelión militar, y corrieron una suerte desigual ${ }^{57}$.

54. ANC, ANC1-886-T-13814, "Informe sobre la Colectividad Agrícola de Barcelona de CNT», 15 de agosto de 1938.

55. ANC, ANC1-886-T-13804, "Acuerdos con el Departamento Administrativo de Guardas Rurales y Forestales de Cataluña», 1 de septiembre de 1938.

56. ANC, ANC1-886-T-13811, "Cartas con secciones y otras instituciones sobre diversos asuntos», 15 de septiembre a 29 de diciembre de 1938; ANC, ANC1-886-T-13813, "Declaraciones juradas de afiliados admitiendo robos», enero de 1939.

57. LaVanguardia, 25 de enero de 1938, p. 7. La información existente se limita a algunos casos. Juan 
Los huertos familiares afrontaban el mismo problema que los de la Colectividad, si cabe con menos recursos. Muchos hortelanos y hortelanas se organizaron para dormir en sus huertos, estableciendo turnos de vigilancia ${ }^{58}$. Pero los asaltos no siempre eran simples correrías de niños y niñas tratando de llevar comida a sus hogares (Domènech, 2012: 161-162, 194). Tal y como denunció la Colectividad, en algunos casos se trataba de grandes grupos organizados, a los que acusaba de distribuir las verduras robadas en el mercado negro (López Sánchez, 2013: 273-274).

La derrota de la República en la batalla del Ebro, certificada a mediados de noviembre de 1938, dejó sellado el destino de la Cataluña republicana. La ofensiva franquista en Cataluña, iniciada el 23 de diciembre, tardó poco más de un mes en alcanzar y ocupar la ciudad de Barcelona y los municipios colindantes, cuyas colectividades agrícolas quedaron inmediatamente disueltas. En algunos casos, como por ejemplo en Molins de Llobregat (Molins de Rei), su colectividad alcanzó a disolverse y repartir equitativamente los ahorros depositados en el banco entre sus integrantes, muchos de los cuales huyeron hacia la frontera francesa (Cases et al., 1989: 210-211). No fue el caso de la Colectividad Agrícola de Barcelona y su Radio, cuyas cuentas bancarias quedaron congeladas y cuya documentación fue incautada por el Servicio de Recuperación de Documentos franquista $^{59}$.

\section{CONCLUSIONES: EN LOS INTERSTICIOS DE LA CIUDADY EN LOS MÁRGENES DE LA HISTORIOGRAFÍA}

Durante los grandes conflictos bélicos del siglo xx y en momentos de crisis económica, la agricultura urbana ha sido adoptada y promovida por distintas instituciones gubernamentales como una estrategia para sortear las dificultades para el abastecimiento, convirtiéndose en un arma de batalla. En cambio, en el caso que nos ocupa, las prácticas agrícolas urbanas surgieron de una base organizativa ciudadana, insertada en los barrios populares y en las periferias de Barcelona, y de carácter mayoritariamente anarcosindi-

Campos Miñarro, activo miembro de la Colectividad en Sant Martí y Gramenet de Besòs, fue arrestado y condenado a muerte, acusado de estar implicado en un homicidio ocurrido cerca de los campos de la colectividad (véase sumario n. ${ }^{\circ} 4.641$ contra Juan Campos Miñarro, Archivo del Tribunal Militar Territorial Tercero). Antonio Liria Rodríguez, que participó como guardia rural en la Colectividad, fue condenado en consejo de guerra a 20 años de cárcel (LóPEZ SÁNCHEZ, 2013: 414).

58. Entrevista con Josep Busó, Girona, 7 de mayo de 2016.

59. La cuenta bancaria de la Colectividad Agrícola de Barcelona y su Radio consta en la "Relación $\mathrm{n}^{\circ} 4$ de cuentas improtegibles» publicada en el Boletín Oficial del Estado, n. ${ }^{\circ} 303,29$ de octubre de 1940, p. 7430 . 
calista. La agricultura en régimen colectivo predominó, pero a medida que la guerra avanzaba y la escasez alimentaria acuciaba, una gran diversidad de iniciativas ciudadanas adoptó prácticas agrícolas en la ciudad, desde huertos de autoconsumo al cultivo de terrenos de fábricas colectivizadas, pasando por la extensión de los huertos escolares.

Este estudio contribuye a la historiografía dedicada a las colectivizaciones agrarias y los abastecimientos durante la guerra civil, centrándose en los procesos desarrollados en zonas urbanas y periurbanas, que apenas han recibido atención en comparación a la «gran agricultura» y las zonas rurales. Como demuestran nuestros resultados, la Colectividad Agrícola de Barcelona ha pasado en buena parte desapercibida a pesar de ser una de las mayores de Cataluña en número de trabajadores y trabajadoras. Y la agricultura de subsistencia realizada fuera de la Colectividad, en parterres, solares o parques reconvertidos, no ha superado una consideración anecdótica y marginal. En parte, dicha invisibilidad es comprensible, puesto que estas prácticas agrícolas han dejado un rastro tenue en los archivos y su cuantificación es complicada, cuando no imposible. Tal y como apuntaba uno de los articulistas de Solidaridad Obrera, los pequeños huertos de Barcelona no se vieron reflejados en las tablas de ninguna gráfica oficial, y solo salen a la luz de forma indirecta, a través de las denuncias registradas por la compañía de aguas, las entrevistas y los testimonios personales, o la revisión de la vasta prensa anarcosindicalista del periodo.

El estudio histórico de la agricultura de subsistencia se enfrenta también a prejuicios actuales. En muchos casos, desde la Administración, la agricultura urbana sigue siendo percibida como un simple pasatiempo, no una actividad productiva; una visión reflejada, por ejemplo, en la prohibición inicial de acudir a los huertos durante el confinamiento causado por la crisis del COVID-19 en marzo y abril de $2020^{60}$. Combatir la visión de esta agricultura como marginal requiere también visibilizar la importancia que los agricultores y agricultoras y sus espacios de cultivo tuvieron en las ciudades durante las crisis del pasado, como por ejemplo la guerra civil o la larga posguerra. Romper, en definitiva, la misma invisibilidad de la que se quejaban amargamente los y las colectivistas barcelonesas en una entrevista publicada en 1937: «Preguntadle a cualquiera que os hable de Barcelona, y tened la seguridad que en un 99 por ciento de los casos, os detallarán todo cuanto existe en la gran capital, pero nada os dirán de los campesinos. Se ignora, por completo su existencia [...] No obstante, los hay también dentro, y no pocos» ${ }^{61}$.

60. «Caos como norma en los huertos de autoconsumo durante el estado de alarma», El Salto, 17 de abril de 2020, https://www.elsaltodiario.com/agricultura/caos-como-norma-huertos-autoconsumoconfinamiento (acceso el 19 de mayo de 2020). Finalmente, dichos desplazamientos fueron autorizados por la Orden SND/381/2020, de 30 de abril, por la que se permite la realización de actividades no profesionales de cuidado y recolección de producciones agrícolas, Boletín Oficial del Estado, n. ${ }^{\circ}$ 121, 1 de mayo de 2020, pp. 30930-30931, https://www.boe.es/eli/es/o/2020/04/30/snd381 
Nuestro estudio se suma a la literatura que demuestra que la agricultura urbana y periurbana se convierte en un recurso fundamental para la seguridad alimentaria en contextos de excepcionalidad (véase Altieri et al., 1999 para el caso de Cuba). Además, los resultados de nuestra investigación señalan que la agricultura urbana no tiene por qué ser una actividad marginal ni a nivel de producción y productividad ni a nivel de personas ocupadas. En términos de productividad, la agricultura a pequeña escala en huertos familiares o colectivos de reducida extensión como la practicada en entornos urbanos se encuentra probablemente entre las más eficientes de todo el ámbito agrario (véase, por ejemplo, Studwell, 2013 para el caso asiático). En términos laborales, esta agricultura de proximidad ha podido absorber también una fuerza de trabajo importante en buena parte responsable de su éxito productivo.

Por otro lado, nuestro estudio también señala la necesidad de ir más allá del paradigma agrario tradicional, centrado en la productividad agrícola y la seguridad alimentaria, y apunta a la importancia de enfocar las relaciones socioambientales en la historiografia agraria (González Esteban, 2014). Por ejemplo, el caso que nos ocupa subraya la importancia del acceso a la tierra, las relaciones de propiedad, la producción de proximidad, la venta directa en los mercados locales sin intermediarios, la creación de puestos de trabajo, o la incorporación masiva de la mujer en las actividades agrícolas, factores cuya importancia se está debatiendo en contextos contemporáneos desde la perspectiva de la soberanía alimentaria.

\section{AGRADECIMIENTOS}

Agradecemos la participación de todas las personas entrevistadas y la colaboración de sus familiares, así como la iniciativa del Consell dels Savis del Museu d'Història de Catalunya por la facilitación de las entrevistas. También queremos agradecer a las personas encargadas de los distintos archivos consultados por su colaboración y ayuda en la investigación.

Queremos agradecer a Alejandro Pérez-Olivares, a David Soto y a las personas editoras y evaluadoras de Historia Agraria sus comentarios a versiones previas del artículo que contribuyeron en gran medida a mejorar el resultado final. También queremos agradecer a Daniel Salas su ayuda con la cartografía. Finalmente, damos las gracias a Pablo González Morandi (Observatori de la Vida Quotidiana) por facilitarnos el acceso a las fotografías de Pérez de Rozas y los reportajes del semanario ¡iCampo!! y a Toni Monné

61. ïCampo!!, 12 de junio de 1937, p. 8. 
Campañá por autorizar la reproducción de las fotografias realizadas por Antoni Campañá y publicadas en La Vanguardia.

Santiago Gorostiza agradece el apoyo del Ministerio de Ciencia e Innovación, mediante el programa «María de Maeztu» de Unidades de Excelencia (CEX2019-000940-M), así como el apoyo puntual del proyecto de investigación «Posguerras civiles: violencia y (re)construcción nacional en España y en Europa, 1939-49» (POS-C-WARS, referencia PGC2018-097724-B-100).

\section{REFERENCIAS}

Altieri, M. A., Companioni, N., Cañizares, K., Murphy, C., Rosset, P., Bourque, M. \& NicholLs, C. I. (1999). The Greening of the "Barrios": Urban Agriculture for Food Security in Cuba. Agriculture and Human Values, 16 (2), 131-140.

BALCELls, A. (2017). Collectivisations in Catalonia and the Region of Valencia during the Spanish Civil War, 1936-1939. Catalan Historical Review, (10), 77-92.

BARTHEl, S., Folke, C. \& Colding, J. (Eds.) (2010). Social-Ecological Memory in Urban Gardens: Retaining the Capacity for Management of Ecosystem Services. Global Environmental Change, 20 (2), 255-265.

Barthel, S., Parker, J., Folke, C. \& Colding, J. (2014). Urban Gardens: Pockets of Social-Ecological Memory. En K. G. Tidball \& M. E. KRASNY (Eds.), Greening in the Red Zone: Disaster, Resilience and Community Greening (pp. 145-158). Dordrecht: Springer Science.

BASSETT, T. J. (1981). Reaping on the Margins: A Century of Community Gardening in America. Landscape, 25 (2), 1-8.

Botella-Rodríguez, E. (2015). Best Practices for Small Farmers in Cuba and Costa Rica in the Global Era (1990-2008). Historia Agraria, (67), 179-215.

Bricall, J. M. (1970). Política econòmica de la Generalitat (1936-1939). Barcelona: Edicions 62 .

Cases, R., Martínez, C., Santacana, C., Simón, A. M. \& Tribó, G. (1989). La Col·lectivització a Molins de Llobregat. En J. L. Adín et al., Col-lectivitzacions al Baix Llobregat (1936-1939) (pp.191-258). Barcelona: Publicacions de l'Abadia de Montserrat.

Charon Cardona, E. \& Markwick, R. D. (2019). The Kitchen Garden Movement on the Soviet Home Front, 1941-1945. Fournal of Historical Geography, (64), 47-59.

Crouch, D. \& WARD, C. (1988). The Allotment: Its Landscape and Culture. London: Faber and Faber.

DomèneCH, J. DE D. (2012). La batalla de l'ou: De quan passàvem gana (1936-1939). Barcelona: Pòrtic. 
EalHam, C. (2005). Class, Culture and Conflict in Barcelona, 1898-1937. London/New York: Routledge/Cañada Blanc Centre.

Fabre, J. \& Huertas, J. M. (1976). Tots els barris de Barcelona IV: Els Tres Turons $i$ els barris de Montjuïc: Can Baró, El Carmel, El Coll, El Poble Sec, Montjü̈ i els seus barris (Can Clos, Can Tunis, Magòria, Port, SEAT, El Polvorí). Barcelona: Edicions 62.

Fernández Casadevante, J. L. \& Morán, N. (2016). Raíces en el asfalto: Pasado, presente y futuro de la agricultura urbana. 2. ${ }^{a}$ ed. Madrid: Libros en Acción.

Ferret i Pujol, J. (1985). L'aprofitament de les aigües subterrànies del Delta del Llobregat: 1933-1983. El Prat de Llobregat: Comunitat d'Usuaris d'Aigües de l'Àrea Oriental del Delta del Riu Llobregat.

Gabriel, P. (2009). Sindicats i Guerra Civil a Catalunya, 1936-1939. En J. SANCHEZ CERVELLÓ (Ed.), El pacte de la no intervenció: La internacionalització de la guerra civil espanyola (pp. 123-156). Tarragona: Universitat Rovira i Virgili.

GALlARDO, J. \& MÁRQUez RodrígueZ, J. M. (1997). Revolución y guerra en Gramenet del Besòs (1936-1939). Santa Coloma de Gramenet: Grupo de Estudios Históricos Gramenet del Besòs.

Garcia Cazorla, C., MilÀ, J. \& Rius, A. (1983). La Colectividad agrícola de Barcelona: Una aportació al fet col-lectivista a Catalunya. En Revolució $i$ Guerra Civil: Recerques a l'Arxiu Històric Nacional de Salamanca (SGC) (pp. 131-143). Tarragona: Departament d'Història Contemporània, Universitat de Barcelona. (Quaderns d'Història Contemporània).

GavaldÀ, A. (2016). Fam de pa i de terra: La col-lectivització agrària a Catalunya. Tarragona: Universitat Rovira i Virgili.

Generalitat DE CATAlunYa (1938a). Ordre que dicta normes encaminades a restringir, en el possible, el consum d'aigua, mentre les circumstàncies ho exigeixin. Diari Oficial de la Generalitat de Catalunya, 28 de abril.

Generalitat de Catalunya (1938b). Decret pel qual és regulada la utilització de terrenys vials, de terrenys amb accés a la via pública, solars o terres ermes, per a convertir-los en horts de tipus familiar. Diari Oficial de la Generalitat de Catalunya, 24 de agosto.

Generalitat de Catalunya (1938c). Ordre que disposa que els camps, els horts i les terres que per manca de braços estiguin abandonats, podran ésser conreats circumstancialment per les persones que no tinguin terres o que les que menen siguin insuficients. Diari Oficial de la Generalitat de Catalunya, 18 de noviembre.

Generalitat DE CATALUNYa (1938d). Ordre que aclareix que en els beneficis de l'Ordre del 10 de Novembre proppassat, relativa a la cessió circumstancial de les hortes i terres abandonades per manca de braços, tenen dret preferent els agricultors professionals. Diari Oficial de la Generalitat de Catalunya, 17 de diciembre. 
Gómez Herráez, J. M. (1999). Patrimonios y huertos familiares: El programa distribuidor en tierras de La Mancha, 1939-1959. Historia Agraria, (17), 153-173.

GonZÁLEZ EstebAN, A. L. (2014). Nuevos paradigmas agrarios: Una aproximación a los fundamentos teóricos de la «soberanía alimentaria». Historia Agraria, (64), 131-159.

GorostiZA, S. (2019). Critical Networks: Urban Water Supply in Barcelona and Madrid during the Spanish Civil War. En S. LAAKKonen, J. R. MCNeILl, R. P. TuCKeR \& T. VuORISAlo (Eds.), The Resilient City in World War II: Urban Environmental Histories (pp. 23-46). Cham: Palgrave Macmillan.

Gorostiza, S., MARCH, H. \& SAURI, D. (2013). Servicing Customers in Revolutionary Times:The Experience of the Collectivized Barcelona Water Company during the Spanish Civil War. Antipode, 45 (4), 908-925.

Hayden-Smith, R. (2014). Sowing the Seeds of Victory: American Gardening Programs of World War I. Jefferson: McFarland \& Company.

Helstosky, C. F. (2004). Fascist Food Politics: Mussolini's Policy of Alimentary Sovereignty. Fournal of Modern Italian Studies, 9 (1), 1-26.

House of Commons (1998). Environment, Transport and Regional Affairs: Fifth Report. https:/publications.parliament.uk/pa/cm199798/cmselect/cmenvtra/560/56002.htm Keshavarz, N., Bell, S., Zilans, A., Hursthouse, A., Voigt, A., Hobbelink, A., ZamMIT, A. et al. (2016). A History of Urban Gardens in Europe. En S. BELL, R. FoxKämper, N. Keshavarz, M. Benson, S. Caputo, S. Noori \& A. Voigt, Urban Allotment Gardens in Europe (pp. 8-32). London/New York: Routledge/Taylor \& Francis Group.

Lawson, L. J. (2014). Garden for Victory!: The American Victory Garden Campaign of World War II. En K. G. Tidball \& M. E. KRASNY (Eds.), Greening in the Red Zone: Disaster, Resilience and Community Greening (pp. 181-195). Dordrecht: Springer Science.

LLovet, J. \& RIU, J. M. (1938). El conreu de la terra com a ocupació secundària dels no agricultors. Arxius de l'Escola Superior d'Agricultura, 4 (1), 51-88.

López SÁncheZ, P. (2013). Rastros de rostros en un prado rojo (y negro): Las Casas Baratas de Can Tunis en la revolución social de los años treinta. Barcelona:Virus.

Maltz, A. (2015). Plant a Victory Garden: Our Food Is Fighting': Lessons of Food Resilience from World War. Fournal of Environmental Studies and Sciences, (5), 392-403.

MALUQUeR DE Motes, J. (2013). La inflación en España: Un índice de precios de consumo, 1830-2012. Madrid: Banco de España.

MARTín RAmos, J. L. (2018). Guerra y revolución en Cataluña, 1936-1939. Barcelona: Crítica.

Martorell i Gil, E. \& Domènech i Domènech, S. (2008). Amb ulls de nena: El dietari de la guerra a la rereguarda. Badalona: Ara Llibres.

MAsjuAn, E. (2000). La ecología humana en el anarquismo ibérico. Barcelona: Icaria. 
McKay, G. (2011). Radical Gardening: Politics, Idealism $\mathcal{E}$ Rebellion in the Garden. London: Frances Lincoln.

MiLLER, M. (2010). Les reines dels mercats: Cultura municipal i gènere al sector del comerç al detall d'aliments de Barcelona. En M. GuÀrdiA \& J. L. OYÓN, Fer ciutat a través dels mercats: Europa, segles XIX $i$ XX (pp. 299-328). Barcelona: Ajuntament de Barcelona/Museu d'Història de Barcelona.

Mok, H. F., Williamson, V. G., Grove, J. R., Burry, K., Barker, S. F. \& Hamilton, A. J. (2014). Strawberry Fields Forever?: Urban Agriculture in Developed Countries: A Review. Agronomy for Sustainable Development, (34), 21-43.

Molle, L. vaN \& SEgers, Y. (2008). Micro-Farming on Other Men's Land Allotments from the $19^{\text {th }}$ to the $21^{\text {st }}$ Century: Belgian History in a Global Perspective. HogeschoolUniversiteit Brussel Working Papers, (23).

Morán, N. \& Hernández AJA, A. (2011). Historia de los huertos urbanos: De los huertos para pobres a los programas de agricultura urbana ecológica. En Actas del I Congreso Estatal de Agricultura Ecológica Urbana y Periurbana. Elche, 6-7 de mayo.

O'NeILL, J. (2003). Socialism, Associations and the Market. Economy and Society, 32 (2), 184-206.

ORTEGA, A. (2009). «Re-ecologizar lo urbano»: Agricultura urbana e historia ambiental. Historia Contemporánea, (39), 453-479.

OYón, J. L. (2008). La quiebra de la ciudad popular: Espacio urbano, inmigración y anarquismo en la Barcelona de entreguerras, 1914-1936. Barcelona: Ediciones del Serbal. PAÜL, V. (2010). El cambio de los usos agrarios del suelo en el actual ámbito metropolitano de Barcelona (del siglo XviII a la actualidad). Investigaciones Geográficas, (53), 145-188.

Peirats, J. (1971). La CNT en la revolución española. Vol. 1. Paris: Ruedo Ibérico.

Puig Vallverdú, G. (2020). La pagesia i la seva revolució: Una anàlisi sobre la conflictivitat i el canvi a la rereguarda catalana durant la Guerra Civil, 1936-1939. Tesis doctoral. Tarragona: Universitat Rovira i Virgili.

SANTACANA, C. (1989). La col-lectivització a L’Hospitalet de Llobregat. En J. L. Adín et al., Col-lectivitzacions al Baix Llobregat (1936-1939) (pp. 489-586). Barcelona: Publicacions de l'Abadia de Montserrat.

SERRA, D. \& SERRA, J. (2003). La guerra quotidiana: Testimonis d'una ciutat en guerra (Barcelona, 1936-1939). Barcelona: Columna.

SERRALlonga I URQuidi, J. (2004). Refugiats $i$ desplaçats dins la Catalunya en guerra, 1936-1939. Barcelona: Base.

Studwell, J. (2013). How Asia Works: Success and Failure in the World's Most Dynamic Region. London: Profile Books.

TORT, J. (2003). Los cambios de nombre de los municipios durante la revolución y la guerra civil españolas (1936-1939): El caso de Cataluña. Scripta Nova. Revista electró- 
nica de geografía y ciencias sociales, (7), 133-156. http://www.ub.es/geocrit/sn/sn133. htm

Wendenburg, C. (2010). Carme Mestres i Rosa Wendenburg: Dues mestres emprenedores en temps difícils. Annals del Patronat d'Estudis Històrics d'Olot i Comarca, (21), 333-351. 
